JURNAL ILMIAH

\title{
PERBEDAAN EFEKTIVITAS SENAM JANTUNG SEHAT DAN SENAM LANSIA TERHADAP PENURUNAN TEKANAN DARAH PADA PASIEN HIPERTENSI DI PUSKESMAS NUSA INDAH KOTA BENGKULU TAHUN 2018
}

\author{
Devi Listiana', Buyung Keraman', Yuki Halik Manto ${ }^{3}$ \\ Dosen Program Studi Ilmu Keperawatan ${ }^{1,2}$ \\ Mahasiswa Program Studi Ilmu Keperawatan ${ }^{3}$ \\ STIKES Tri Mandiri Sakti Bengkulu \\ email :devilistiana01@gmail.com ${ }^{1}$ \\ buyungkeraman@yahoo.com ${ }^{2}$ \\ yukyyayan@gmail.com ${ }^{3}$
}

\begin{abstract}
ABSTRAK
Hipertensi adalah penyakit kelainan jantung dan pembuluh darah yang ditandai dengan peningkatan tekanan darah. Salah satu terapi non farmakologi hipertensi adalah olahraga. Senam lansia adalah serangkaian gerak nada yang teratur dan terarah serta terencana yang dilakukan secara tersendiri atau kelompok. Tujuan penelitian untuk mempelajari perbedaan efektivitas senam lansia dan senam jantung sehat terhadap penurunan tekanan darah pada pasien hipertensi di Puskesmas Nusa Indah Kota Bengkulu tahun 2018. Penelitian ini menggunakan rancangan quasi eksperimental pre and post test. Populasi dalam penelitian ini adalah seluruh pasien hipertensi pada anggota senam di Puskesmas Nusa Indah Kota Bengkulu tahun 2018. Pengambilan sampel diambil dari seluruh populasi. Hasil penelitian menggunakan uji Shapiro-Wilk menunjukkan bahwa nilai $p=0,247(>a=0,05)$ artinya tidak ada perbedaan efektivitas senam lansia dan senam jantung sehat terhadap penurunan tekanan darah sistolik pada pasien hipertensi di Puskesmas Nusa Indah Kota Bengkulu tahun 2018. Nilai $p=0,450(>a=0,05)$ artinya tidak ada perbedaan efektivitas senam lansia dan senam jantung sehat terhadap penurunan tekanan darah diastolik pada pasien hipertensi di Puskesmas Nusa Indah Kota Bengkulu tahun 2018. Diharapkan kepada pasien hipertensi untuk lebih teratur mengikuti kegiatan senam dalam menjaga kestabilan tekanan darah.
\end{abstract}

Kata Kunci: Hipertensi, Senam Lansia, Senam Jantung Sehat.

\begin{abstract}
Hypertension is a heart disease and blood vessels that are marked by an increase in blood pressure. One non-pharmacological therapy for hypertension is boarding. Elderly gymnastics is a series of regular and directed and planned tone movements performed individually or groups. The general objective in this study was to study the differences in the effectiveness of elderly gymnastics and healthy heart gymnastics to decrease blood pressure in hypertensive patients at the Nusa Indah Health Center Bengkulu City in 2018. Was the amount of this study using a quasi experimental design of pre and post test. The population in this study were all hypertensive patients in gymnastics members at the Nusa Indah Health Center in Bengkulu City in 2018.Sampling was taken from the entire
\end{abstract}


population. Has research using the Shapiro-Wilk test showed that the value $p=0.247$ $(>a=0.05)$ meaning that there was no difference in exercise effectiveness. Elderly and healthy cardiac gymnastics against a reduction in systolic blood pressure in patients hypertension at Nusa Indah Health Center Bengkulu City in 2018. The value $p=0.450$ $(>a=0.05)$ means that there is not difference in the effectiveness of elderly gymnastics and healthy heart gymnastics against a decrease in diastolic blood pressure in hypertensive patients at Nusa Indah Health Center in Bengkulu City in 2018. Expected to hypertensive patients to more regularly take part in gymnastics activities to maintain blood pressure stability.

Keywords : Elderly Gymnastics, Healthy Heart Gymnastics, Hypertension.

\section{PENDAHULUAN}

Salah satu problema kesehatan utama di negara maju dan berkembang adalah penyakit kardiovaskular, sehingga menjadi penyebab kematian nomor satu di dunia begitu juga di Indonesia, baik untuk lakilaki maupun untuk perempuan. Menurut WHOtahun 2014 ada 19,4juta orang meninggalkarenapenyakitkardiovaskuler.

Dari data WHO (World Health Organization) padatahun 2014 menunjukkan bahwa terdapat 9.4 juta orang dari 1 milyar penduduk di dunia yang meninggal akibat gangguan sistem kardiovaskular. Prevalensi hipertensi di negara maju sebesar $35 \%$ dan di negara berkembang sebesar $40 \%$ dari populasi dewasa. Pada tahun 2025 diperkirakan kasus hipertensi terutama di Negara berkembang akan mengalami peningkatan $80 \%$ dari 639 juta kasus di tahun 2000, yaitu menjadi 1,15 milyar kasus. Prediksi ini didasarkan pada angka penderita hipertensi dan bertambahnya penduduk saat ini.

Kecenderungan penyakit menular terus meningkat dan telah mengancam sejak usia muda. Selama dua dekade terakhir ini, telah terjadi transisi epidemiologis yang signifikan, penyakit tidak menular telah menjadi beban utama, meskipun beban penyakit menular masih berat juga. Indonesia sedang mengalami double burden penyakit, yaitu penyakit tidak menular dan penyakit menular sekaligus. Penyakit tidak menular utama meliputi hipertensi, diabetes melitus, kanker dan Penyakit Paru
Obstruktif Kronik (PPOK). Jumlah kematian akibat rokok terus meningkat dari $41,75 \%$ menjadi $59,7 \%$ di 2007 . Selain itu dalam survei ekonomi nasional 2006 disebutkan penduduk miskin menghabiskan $12,6 \%$ penghasilannya untuk konsumsi rokok (Depkes RI, 2015).

Menurut American Heart Association (AHA), 2014 penduduk Amerika yang berusia di atas 20 tahun menderita hipertensi telah mencapai angka hingga 74,5 juta jiwa, namun hampir sekitar 9095\% kasus tidak diketahui penyebabnya. Hipertensi merupakan silent killer dimana gejala dapat bervariasi pada masing-masing individu dan hampir sama dengan gejala penyakit lainnya.Gejala-gejalanya itu adalah sakit kepala/rasa berat di tengkuk, mumet (vertigo), jantung berdebar-debar, mudah lelah, penglihatan kabur, telinga berdenging (tinnitus), dan mimisan (AHA, 2014).

Sampai saat ini, hipertensi masih merupakan tantangan besar di Indonesia. Betapa tidak, hipertensi merupakan kondisi yang sering ditemukan pada pelayanan kesehatan primer kesehatan. Hal itu merupakan masalah kesehatan dengan prevalensi yang tinggi, yaitu sebesar 25,8\% (Riskesdas, 2013).

Berdasarkan hasil pengukuran tekanandarah, prevalensi hipertensi pada penduduk umur 18 tahun ke atas tahun 2007 di Indonesia adalah sebesar 31,7\%. Menurut provinsi, prevalensi hipertensi tertinggi di Kalimantan Selatan $(39,6 \%)$ dan terendah di Papua Barat $(20,1 \%)$. Sedangkan jika dibandingkan dengan tahun 
2013 terjadi penurunan sebesar 5,9\% (dari $31,7 \%$ menjadi $25,8 \%$ ). Penurunan ini bisa terjadi dari berbagai macam faktor, seperti alat pengukur tensi yang berbeda, masyarakat yang sudah mulai sadar akan bahaya penyakit hipertensi. Prevalensi tertinggi di Provinsi Bangka Belitung $(30,9 \%)$, dan Papua yang terendah $(16,8) \%)$. Prevalensi hipertensi di Kota Bengkulu (54,66\%). Prevalensi hipertensiI ndonesia yang didapat melalui kuesioner terdiagnosis tenaga kesehatan sebesar 9,4 $\%$, yang didiagnosis tenaga kesehatan atau sedang minum obats ebesar 9,5\%. Jadi, ada $0,1 \%$ yang minum obat sendiri (Riskesdas, 2013).

Pembangunan kesehatan pada hakekatnya adalah upaya yang dilaksanakan oleh semua komponen Bangsa Indonesia yang bertujuan untuk meningkatkan kesadaran, kemauan, dan kemampuan hidup sehat bagi setiap orang agar terwujud derajat kesehatan masyarakat yang setinggi-tingginya, sebagai investasi bagi pembangunan sumber daya manusia yang produktif secara sosial dan ekonomis. Keberhasilan pembangunan kesehatan sangat ditentukan oleh kesinambungan antar upaya program dansektor, serta kesinambungan dengan upaya-upaya yang telah dilaksanakan oleh periodes ebelumnya (Depkes RI,2015).

Hipertensi atau tekanan darah tinggi dapat ditangani dengan pengobatan farmakologi danpengobatan non farmakologi, pengobatan farmakologi dapat ditangani melalui obat golongan anti hipertensi seperti diuretik, betablokerdan vasodilator (Smolin, 2013).

Beberapa penderita hipertensi menolak untuk disiplin meminum obat farmakologi karena efek samping seperti batuk, pusing, disfungsi seksual, aritmia jantung, dan retensicairan, sehingga para penderita hipertensi memilih pengobatan non farmakologi dalam mengontrol tekanan darah untuk mengurangi efek samping tersebut (Nurrahmani, 2014).

Penatalaksanaan non-farmakologi misalnya dengan menjalankan pola hidup sehat, menurunkan berat badan sampai batas ideal dengan cara membatasi makan dan mengurangi penggunaan garam, menghentikan pemakaian alkohol dan narkoba, hidup dengan pola yang sehat, istirahat yang cukup, berhenti merokok, mengelola stres, melakukan olahraga yang tidak terlalu berat secara teratur (Susilo \& Wulandari, 2010).

Melakukan olahraga seperti senam lansia mampu mendorong jantung bekerja secara optimal, olahraga untuk jantung mampu meningkatkan kebutuhan energi oleh sel, jaringan dan organ tubuh akibat peningkatan tersebut akan meningkatkan aktivitas pernafasan dan otot rangka, dari peningkatan aktivitas pernafasan akan meningkatkan aliran balik vena sehingga menyebabkan peningkatan volume sekuncup yang akan langsung meningkatkan curah jantung sehingga menyebabkan tekanan darah arteri meningkat, setelah tekanan darah arteri meningkat akan terjadi fase istirahat terlebih dahulu, akibat dari fase ini mampu menurunkan aktivitas pernafasan dan otot rangka dan menyebabkan aktivitas saraf simpatis dan epinefrin menurun, namun aktivitas saraf simpatis meningkat, setelah itu akan menyebabkan kecepatan denyut jantung menurun, volume sekuncup menurun, vasodilatasi arteriolvena, karena penurunan ini mengakibatkan penurunan curah jantung dan penurunan resistensi perifer total, sehingga terjadinya penurunan tekanan darah (Sherwood, 2006).

Jumlah penduduk Kota Bengkulu berusia > 18 tahun adalah 225.729 orang, melakukan pemeriksaan tekanan darah berjumlah 11.628 atau $(5,15 \%)$. Penduduk yang didiagnosa hipertensi berjumlah 3.647 orang atau $31,36 \%$ pada tahun 2015 . Terjadi peningkatan jumlah penduduk yang terdeteksi menderita hypertensi sebesar $3,12 \%$ karena tahun 2014 penduduk penderita hypertensi 28,24\% (Dinkes Provinsi Bengkulu, 2015). Berdasarkan data Puskesmas Nusa Indah (2018), jumlah peserta yang tergabung dalam kegiatan senam setiap minggu yang dilaksanakan di 
Puskesmas Nusa Indah berjumlah 37 orang yang terdiagnosa menderita hipertensi. Adapun rumusan masalah penelitian ini apakah ada perbedaan efektivitas senam lansia dansenam jantung sehat terhadap perubahan tekanan darah pada pasien hipertensi di Puskesmas Nusa Indah Kota Bengkulu?. Tujuanpenelitian untuk mempelajari perbedaan efektivitas senam lansia dan senam jantung sehat terhadap perubahan tekanan darah pada pasien hipertensi di Puskesmas Nusa Indah Kota Bengkulu.

\section{METODE PENELITIAN}

Penelitian dilaksanakan di Puskesmas Nusa Indah Kota Bengkulu yang beralamat di Jl. Mawar Kelurahan Nusa Indah Kecamatan Ratu Agung Kota Bengkulu dan waktu penelitian dilaksanakan pada bulan Agustus tahun 2018. Jenis penelitian ini adalah penelitian dengan rancangan quasi eksperimental pre and post test. Populasi yang digunakan dalam penelitian ini adalah

Tabel 1

Distribusi Frekuensi Nilai Tekanan Darah Sistolik dan Diastolik Sebelum Melakukan Senam Lansia dan Senam Jantung Sehat

\begin{tabular}{lcccccc}
\hline \multicolumn{1}{c}{ Tekanan } & \multicolumn{3}{c}{ Sebelum } & & \multicolumn{3}{c}{ Sesudah } \\
\cline { 2 - 7 } Darah & Mean & Median & SD & Mean & Median & SD \\
\hline $\begin{array}{l}\text { Sistolik } \\
\text { SenamLansia }\end{array}$ & 147.44 & 147.50 & 8.597 & 141.78 & 142.00 & 6.044 \\
$\begin{array}{l}\text { Diastolik } \\
\text { SenamLansia }\end{array}$ & 94.83 & 96.50 & 6.767 & 91.00 & 92.50 & 6.417 \\
$\begin{array}{l}\text { Sistolik } \\
\text { SenamJantung sehat }\end{array}$ & 150.78 & 151.00 & 8.475 & 139.28 & 138.50 & 6.667 \\
$\begin{array}{l}\text { Diastolik } \\
\text { Senam }\end{array}$ & 97.61 & 98.50 & 6.289 & 89.50 & 89.00 & 5.316 \\
Jantung sehat & & & & & & \\
\hline
\end{tabular}

Dari tabel statistik di atas dapat diketahui tekanan darah sistolik sebelum senam lansia rata-rata $=147,44$, median $=$ 147,5 dan standar deviasi $=8,597$. Tekanan darah diastolik sebelum senam lansia ratarata $=94,83$, median $=96,5$ dan standar deviasi $=6,767$. Tekanan darah sistolik sesudah senam lansia rata-rata $=141,78$, median $=142$ dan standar deviasi $=6,044$. Tekanan darah diastolik sesudah senam lansia rata-rata $=91$, median $=92,5$ dan seluruh pasien dengan penyakit hipertensi pada anggota senam yang berjumlah 36orang. Pengambilan sampel diambil dari seluruh populasi. Penelitian ini menggunakan data primer. Uji normalitas data dalam penelitian ini menggunakan metode Shapiro Wilk. Analisis data dengan Analisa Univariat dan Analisa Bivariat dengan uji Independent sample t-Test.

\section{HASIL PENELITIAN}

\section{Analisis Univariat}

Analisis univariat bertujuan untuk menggambarkan distribusi frekuensi variabel penelitian dengan menggunakan statistik deskriptif. Variabel yang dianalisis adalah nilai tekanan darah sistolik dan diastolik sebelum dan sesudah melakukan senam lansia dan nilai tekanan darah sistolikdan diastolik sebelum dan sesudah melakukan senam jantung sehat.

standar deviasi $=6,417$. Tekanan darah sistolik sebelum senam jantung sehat ratarata $=150,78$, median $=151$ dan standar deviasi $=8,475$. Tekanan darah diastolik sebelum senam jantung sehat rata-rata $=$ 97,61, median $=98,5$, dan standar deviasi $=$ 6,289. Tekanan darah sistolik sesudah senam jantung sehat rata-rata $=139,28$, median $=138,5$ danstandardeviasi $=6,667$. Tekanan darah diastolik sesudah senam 
jantung sehat rata-rata $=89,5$, median $=89$ dan standar deviasi $=5,316$.

\section{Analisis Normalitas Data}

Uji normalitas data dalam penelitian ini menggunakan metode Shapiro Wilk.
Metode ini menggunakan data dasar yang belum diolah dalam tabel distribusif rekuensi, kemudian dibagi dua dalam dua kelompok untuk dikonversid alam ShapiroWil

Tabel 2

Uji Normalitas Data

\begin{tabular}{lccccc}
\hline & \multicolumn{3}{c}{ Shapiro-Wilk } & \multirow{2}{*}{ Keterangan } \\
\cline { 2 - 4 } & Statistic & df & Sig. & \\
\hline $\begin{array}{l}\text { Tekanan Darah Sistolik } \\
\text { Sebelum Senam Jantung }\end{array}$ & 0.957 & 18 & 0.538 & \multirow{2}{*}{ Berdistribusi Normal } \\
$\begin{array}{l}\text { Tekanan Darah Diastolik } \\
\begin{array}{l}\text { Sebelum Senam Jantung } \\
\text { Tekanan Darah Sistolik }\end{array}\end{array}$ & 0.949 & 18 & 0.406 & Berdistribusi Normal \\
$\begin{array}{l}\text { Sesudah Senam Jantung } \\
\text { Tekanan Darah Diastolik }\end{array}$ & 0.979 & 18 & 0.938 & Berdistribusi Normal \\
$\begin{array}{l}\text { Sesudah Senam Jantung } \\
\text { Tekanan Darah Sistolik }\end{array}$ & 0.936 & 18 & 0.242 & Berdistribusi Normal \\
$\begin{array}{l}\text { Sebelum Senam Lansia } \\
\text { Tekanan Darah Diastolik }\end{array}$ & 0.961 & 18 & 0.616 & Berdistribusi Normal \\
$\begin{array}{l}\text { Sebelum Senam Lansia } \\
\text { Tekanan Darah Sistolik }\end{array}$ & 0.929 & 18 & 0.184 & Berdistribusi Normal \\
$\begin{array}{l}\text { Sesudah Senam Lansia } \\
\text { Tekanan Darah Diastolik }\end{array}$ & 0.93 & 18 & 0.192 & & Berdistribusi Normal \\
Sesudah Senam Lansia & 0.926 & 18 & 0.163 & & Berdistribusi Normal \\
\hline
\end{tabular}

Hasil test of normality data tekanan darah sistolik dan diastolik sebelum dan sesudah perlakuan signifikan untuk uji Shapiro-Wilk. Dengan hipotesis yang di uji adalah:

Ho: sampel berasal dari populasi berdistribusi normal

Ha : sampel berasal dari populasi tidak berdistribusi normal.

Hasil test of normality di atas didapat nilais ignifikan pada uji Shapiro-Wilk dengan nilai sig.(p) semuanya p-value $>\alpha=0,05$ berarti semua tidak signifikan, maka Ho diterima dan Ha ditolak. Jadi, sampel berasal dari populasi berdistribusi normal pada taraf signifikan p-value 0,05 . Sehingga memenuhi syarat untuk dilakukan uji t dua sampel bebas (independent sample t test).

\section{Analisis Bivariat}

Analisis bivariat menggunakan Independent Sample Test. Uji ini digunakan untuk menentukan ada tidaknya perbedaan rata-rata dua sampel bebas.

Tabel 3

Independent Sample Test TekananDarahSistolik dan Diastolik Sesudah Perlakuan

\begin{tabular}{lcccc}
\hline & f & Sig & t & Sig (2-tiled) \\
\hline Tekanan darah sistolik & 0.01 & 0.919 & -1.179 & 0.247 \\
Tekanan darah diastolic & 1.779 & 0.191 & -0.764 & 0.45 \\
\hline
\end{tabular}

Dari tabel independent sample test $\mathrm{di}$ untuk menguji asumsi dasar dari uji t bahwa atas dapat diketahui tekanan darah sistolik varian kedua kelompok adalah sama. dan diastolik sesudah perlakuan. $\mathrm{F}$ adalah 
Hipotesis:

$\mathrm{H}_{0}$ : kedua kelompok memiliki varian yang sama

Ha: kedua kelompok memiliki varian yang tidak sama.

Dari hasil analisis di atas untuk tekanan darah sistolik didapatnilai $\mathrm{F}=0,010$ dengannilai sig. $(p)=0,919>\alpha=0,05$, maka Ho diterima,dan dari hasil analisis diatas untuk tekanan darah diastolik didapat nilai $\mathrm{F}=1,779$ dengannilai sig. $(\mathrm{p})=0,191>\alpha=0,05$, maka Ho diterima. Jadi kedua kelompok memiliki varian yang sama. Uji selanjutnya menggunakan nilai pada kolom equal variances assumed.

Dari hasil analisis untuk tekanan darah sistolik didapat nilai $\mathrm{t}=-1,179$ dimutlakkan menjadi $\mathrm{t}=1,179$ dengan nilai sig.(p) $=0,247>\alpha=0,05$, maka Ha ditolak dan Ho diterima, dan dari hasil analisis untuk tekanan darah diastolik didapat nilai $\mathrm{t}=$ 0,764 dimutlakkan menjadi $\mathrm{t}=0,164$ dengan nilai sig. $(\mathrm{p})=0,450>\alpha=0,05$, maka $\mathrm{Ha}$ ditolakdan Ho diterima.

Jadi, tidak terdapat perbedaan efektivitas senam lansia dan senam jantung sehat terhadap penurunan tekanan darah pada pasien hipertensi di puskesmas Nusa Indah Kota Bengkulu tahun 2018.

\section{PEMBAHASAN}

Hasil penelitian menunjukkan bahwa rata - rata tekanan darah sistolik sebelum dilakukan intervensi senam lansia adalah 147,44 dengan standar deviasi 8,597 dan rata - rata tekanan darah diastolik sebelum dilakukan intervensi senam lansia adalah 94,83dengan standar deviasi 6,767. Setelah dilakukan intervensi senam lansia rata rata tekanan darah sistolik adalah 141,78 dengan standar deviasi 6,044 dan rata - rata tekanan darah diastolik setelah dilakukan intervensi senam lansia 91,0 dengan standar deviasi 6,417. Hal ini menunjukkan bahwa adanya penurunan tekanan darah sistolik dan diastolik setelah dilakukan intervensi senam lansia pada pasien hipertensi di Puskesmas Nusa Indah Kota Bengkulu.

Penelitian serupa juga dilakukan oleh Izhar (2017) yang menunjukkan bahwa $p$ - value TD systole sebelum dan setelah senam lansia $=0,002(\mathrm{p}<\alpha)$, artinya ada pengaruh senam lansia terhadap tekanan darah systole lansia dengan hipertensi di Panti social Tresna Werdha Budi Luhur Kota Jambi. Sejalan dengan itu hasil TD diastole sebelum dan setelah senam lansia didapatkan $p$-value $=0,003(\mathrm{p}<\alpha)$, artinya ada pengaruh senam lansia terhadap tekanan darah diastole lansia dengan hipertensi di Panti Sosial Tresna Werdha Budi Luhur Kota Jambi.

Olahraga yang teratur dibuktikan dapat menurunkan tekanan perifer, sehingga dapat menurunkan tekanan darah. Dengan olahraga, akan timbul perasaan santai, dapat menurunkan berat badan, sehingga dapat menurunkan tekanan darah.

Hasil penelitian menunjukkan bahwa rata - rata tekanan darah sistolik sebelum dilakukan intervensi senam jantung sehat adalah 150,78 dengan standar deviasi 8,475 dan rata - rata tekanan darah diastolik sebelum dilakukan intervensi senam jantung sehat adalah 97,61 dengan standar deviasi 6,289. Setelah dilakukan intervensi senam jantung sehat rata - rata tekanan darah sistolik adalah 139,28 dengan standar deviasi 6,667 dan rata - rata tekanan darah diastolik sesudah intervensi senam jantung sehat adalah 89.50 dengan standar deviasi 5,316. Hasil ini menunjukkan bahwa adanya penurunan nilai rata - rata tekanan darah sistolik dan diastolik setelah dilakukan intervensi senam jantung sehat.

Hasil penelitian ini sesuai dengan pendapat Puspa Ayu Priadi (2016) yang menyatakan bahwa rata - rata perbedaan tekanan darah sistolik sebelum dan sesudah intervensi adalah 19,333. Hasil uji statistik menyatakan terdapat pengaruh senam jantung sehat terhadap tekanan darah dengan nilai $\mathrm{p}=0,000$ dan nilai Eta 0,73 . Sedangkan rata - rata perbedaan nilai tekanan darah diastolik sebelum dan sesudah intervensi adalah 11,333. Hasil uji statistik menyatakan terdapat pengaruh senam jantung sehat terhadap tekanan darah dengan nilai $\mathrm{p}=0,003$ dan nilai Eta 0,45 . 
Hasil analisis pada tekanan darah sistolik sesudah perlakuan didapat nilai $\mathrm{t}=$ 1,179 dengan nilai sig. $(p)=0,247>\alpha=0,05$ dan pada tekanan darah diastolik didapat hasil nilai $\mathrm{t}=0,164$ dengan nilai sig. $(p)=0,450>\alpha=0,05$, hal ini menunjukan bahwa tidak terdapat perbedaan efektivitas senam lansia dan senam jantung sehat terhadap penurunan tekanan darah pada pasien hipertensi.

Dalam penelitian semua responden melakukan senam dengan mengikuti semua gerakan yang dilakukan instruktur. Semua peserta yang tergabung dalam sampel merupakan pasien hipertensi yang secara teratur melakukan kegiatan senam dan dapat disimpulkan bahwa senam jantung sehat dan senam lansia sama - sama efektif untuk menurunkan tekanan darah sistolik dan diastolikpada pasien hipertensi di Puskesmas Nusa Indah Kota Bengkulu tahun 2018.

Penelitian serupa juga dilakukan oleh Ida Bagus Gede Brahmandita Saputra (2016) dengan judul "Perbandingan Senam Jantung Sehat Dengan Senam Lansia Terhadap Penurunan Tekanan Darah Lansia Penderita Hipertensi Grade I" yang menunjukkan bahwa terdapat penurunan tekanan darah sistolik yang bermakna pada kelompok senam jantung sehat $(\mathrm{p}<0,05)$ dan kelompok senam lansia $(p<0,05)$. Penurunan tekanan darah sistolik juga menunjukkan hasil yang signifikan pada masing-masing kelompok perlakuan $(\mathrm{p}<0,05)$.

Darmojo (2006) menjelaskan bahwa peningkatan oksigen dan glukosa dapat untuk membentuk ATP dapat dilakukan dengan olahraga. Olahraga menyebabkan pembuluh darah mengalami pelebaran (vasodilatasi) serta terbukanya pembuluh darah yang belum terbuka sehingga aliran darah ke sel dan jaringan meningkat.

Hal ini juga sesuai dengan teori Smolin (2009), yang menjelaskan bahwa olahraga aerobik seperti senam dapat menurunkan resiko atherosclerosis dengan memperkuat otot jantung dimana denyut jantung mengalami penurunan dan mengurangi kerja jantung. Hal itu bisa menurunkan tekanan darah dan meningkatkan level kolesterol HDL (yang sehat) dalam darah, yang keduanya mengurangi resiko atherosclerosis.

Terjadi kontrol terintegrasi pada tekanan darah dikendalikan secara reflex oleh system saraf otonom, yang disebut reflex baroreseptor yang berlokasi di aortic arch dan arteri karotid (Kenney et al, 2011). Fungsi dari baroreseptor adalah sebagai pengontrol pada perubahan akut tekanan darah (Brown et al, 2006 dalam Puspa Ayu Priadi 2016).

Setelah olahraga, terjadi penurunan aktivitas kardiovaskular. Baroreseptor akan merespon untuk memberikan penurunan denyut jantung dan kontraktilitas jantung, dan penurunan tekanan darah. Baroreseptor bertugas untuk mengembalikan keadaan tubuh menjadi seimbang atau homeostasis. Penurunan darah akan turun sampai dibawah normal dan berlangsung selama 30 - 120 menit. Penurunan tekanan darah terjadi karena terjadi pelebaran dan relaksasi pada pembuluh darah (Bafirman, 2007 dalam Puspa Ayu Priadi 2016).

Dari penelitian yang dilakukan menunjukkan bahwa senam lansia dan senam jantung sehat dapat menurunkan tekanan darah pada pasien hipertensi sehingga tenaga kesehatan khususnya profesi perawat dapat melakukan edukasi kepada pasien hipertensi untuk melakukan olahraga secara teratur dan dijadikan salah satu terapi non farmakologi pada pasien hipertensi.

Penatalaksanaan non farmakologi misalnya dengan menjalankan pola hidup sehat, menurunkan berat badan sampai batas ideal dengan cara membatasi makan dan mengurangi penggunaan garam, menghentikan pemakaian alkohol dan narkoba, hidup dengan pola yang sehat, istirahat yang cukup, berhenti merokok, mengelola stress, melakukan olahraga yang tidak terlaku berat seperti senam secara teratur (Susilo \& Wulandari,2011). 


\section{KESIMPULAN}

1. Rata - rata tekanan darah sistolik sebelum dilakukan senam lansia adalah 147,44 dan rata - rata tekanan darah diastolik adalah 94,83.

2. Rata - rata tekanan darah sesudah dilakukan senam lansia adalah 141,78 dan rata - rata tekanan darah diastolik adalah 91,00.

3. Rata - rata tekanan darah sistolik sebelum dilakukan senam jantung sehat adalah 150,78 dan rata - rata tekanan darah diastolik adalah 97,61.

4. Rata - rata tekanan darah sistolik sesudah dilakukan senam jantung sehat adalah 139,28 dan rata - rata tekanan darah diastolik adalah 89,50.

5. Ada perbedaan efektivitas senam jantung sehat dan senam lansia terhadap penurunan tekanan darah pada pasien hipertensi di Puskesmas Nusa Indah Kota Bengkulu Tahun 2018.

\section{DAFTAR PUSTAKA}

Darmojo R.B, Hadi-Martono. (2014). Buku Ajar Geriatri (Ilmu Kesehatan Usia Lanjut). (Edisi ke 5). Jakarta: FKUI.

Depkes RI (2015). Profil Kesehatan Indonesia tahun 2014. Jakarta : Depkes RI.

Dinkes Provinsi Bengkulu (2015). Profil Kesehatan Provinsi Bengkulu Tahun 2015. Dinas Kesehatan Provinsi Bengkulu.

Izhar, M. Dody. (2017). Pengaruh Senam Lansia Terhadap Tekanan Darah Di Panti Sosial Tresna Werdha Budi Luhur Jambi. Vol.17 No.1 Jurnal Ilmiah Universitas Batanghari Jambi.

Nurrahmani. (2014). Pelayanan Keperawatan Bagi Penderita Hipertensi Secara Terpadu. Yogyakarta: Graha Ilmu.

Priadi, Puspa Ayu. (2016). Pengaruh Senam Jantung Sehat Terhadap Tekanan Darah Pada Lansia Hipertensi Di PSTW Budi Mulia 03 Margaguna Jakarta Selatan. Skripsi.
Universitas Islam Negeri Syarif Hidayatullah Jakarta.

Riset Kesehatan Dasar (Riskesdas), 2013. Pedoman Pewawancara Petugas Pengumpul Data. Jakarta : Depkes RI Saputra, Ida Bagus Gede Brahmandita. (2016). Perbandingan Senam Jantung Sehat dengan Senam Lansia Terhadap Penurunan Tekanan Darah Lansia Penderita Hipertensi Grade I di Desa Dauh Puri Kauh Denpasar Barat. Skripsi. Fakultas Kedokteran Universitas Udayana.

Sherwood. (2006). Buku Ajar Keperawatan Medikal Bedah Brunner \&Suddarth. Jakarta : EGC.

Smolin. (2013). Nursing Outcomes Classification (NOC). St Louis, Missouri : Mosby.

Susilo dan Wulandari (2010). Keperawatan Kardiovaskuler. Jakarta: Salemba Medika.

World Health Organization (WHO), (2014). Prevalence hypertension and cardiovascular disease. 